\title{
The Productivity of European Life Insurers: Best-Practice Adoption vs. Innovation
}

\author{
Fabio Bertoni and Annalisa Croce \\ Department of Management, Economics and Industrial Engineering, Politecnico di Milano-Piazza \\ Leonardo da Vinci 32, Milan 20133, Italy. \\ E-mails: fabio.bertoni@polimi.it; annalisa.croce@polimi.it
}

The aim of this work is to investigate the drivers of productivity evolution in the European life insurance industry in the aftermath of the enforcement of the Third Directive. We apply Data Envelopment Analysis (DEA) to a panel of 602 life insurance companies operating in five European countries (Germany, France, Italy, Spain and the U.K.) between 1997 and 2004 and develop a generalized Malmquist efficiency decomposition to gauge the relative importance of two sources of productivity change: the improvement of best-practices via innovation, and the adoption of practices currently adopted by local or foreign best-in-class insurers. We find that productivity increased on an annual basis by 6.71 per cent; the increase has been mostly due to innovation in best-practices ( 6.67 per cent), while bestpractice adoption contributed by a mere 0.04 per cent. Our findings also indicate that, over the period of our analysis, innovation of best-practices was attributable to technological change. We find no evidence, instead, that productivity has been driven by a shift in the risk profile of insurers.

The Geneva Papers (2011) 36, 165-185. doi:10.1057/gpp.2011.1

Keywords: Data Envelopment Analysis; life insurance; Third Directive; Malmquist index; efficiency decomposition

\section{Introduction}

Insurance companies in Europe witnessed, since the early 1990s, a dramatic regulatory change process. This huge policy-making effort was motivated by the rationale that, in an increasingly competitive environment, business practices would have gone through a harmonization process and that insurance companies would have improved their products and processes and, eventually, they would have become more productive.

A vast empirical literature, based on different techniques, samples and time periods, tried to verify the extent to which these objectives have been achieved. ${ }^{1}$ Results are pretty consistent in indicating that an increase in productivity took place, albeit estimates on its size and dynamics vary substantially across different studies. The literature also evidenced significant cross-country differences, which highlight that a comprehensive view of the phenomenon can only be obtained by taking a crosscountry perspective, and that no country should be considered as "representative" of

\footnotetext{
${ }^{1}$ For a comprehensive overview on the measurement of efficiency and productivity in the insurance industry see, for instance, Cummins and Weiss (2000) and Eling and Luhnen (2008).
} 
166

Europe as a whole. ${ }^{2}$ The relatively few studies carried out on an international sample found that, besides the importance of country-specific factors, productivity is significantly influenced by insurer's size, specialisation and ownership. ${ }^{3}$ Size, in particular, is found to play a crucial role. A scale efficient firm operates at constant returns to scale (CRS) while scale inefficiency can yield to either decreasing returns to scale DRS (when the scale is "too large") or increasing returns to scale (IRS) (when the scale is "too small"). Most studies agree that small life insurers operate with IRS (i.e. that below a certain size threshold, insurers are inefficient). There is also some, albeit less unanimous, evidence of the existence of a size threshold above which DRS appear, causing a decline in productivity. ${ }^{4}$

One aspect which the literature has largely neglected is how insurance companies improved their productivity to cope with increased competition. In this study, in particular, we distinguish between two fundamentally different drivers of productivity improvement, which correspond to completely different strategies: best-practice innovation and best-practice adoption. On the one hand, insurers exposed to a higher competitive pressure might try to improve current best-practices through the introduction of new products and the development of more efficient processes. We call this strategy bestpractice innovation. On the other hand, individual insurers may improve their productivity simply by imitating best-practices currently adopted by other insurers. We call this strategy best-practice adoption. We also distinguish between three different types of adoption: best-practice may originate within insurer's country (local adoption), may be inspired by practices adopted outside national borders (global adoption), or can be driven by the adjustment of size towards a more efficient level (scale adoption).

In particular, in this work, we empirically measure the contribution of (different types of) best-practice adoption and best-practice innovation to total factor productivity (TFP) increases of European life insurance companies after the enactment of the Third Directive. To do so we rely upon Data Envelopment Analysis (DEA), a technique that allows the identification of a best-practice technology frontier. ${ }^{5}$ Several reasons make DEA preferable to the other approach which is commonly used to identify the best-practices technology frontiers: Stochastic Frontiers Analysis (SFA). ${ }^{6}$

${ }^{2}$ See for instance studies carried out in Austria (Ennsfellner et al., 2004), Britain (Rees and Kessner, 1999), France (Fecher et al., 1993), Italy (Cummins et al., 1996), Germany (Kessner and Polborn, 1999; Rees and Kessner, 1999; Mahlberg and Url, 2000) and Spain (Fuentes et al., 2001; Cummins and Rubio-Misas, 2006).

${ }^{3}$ See for instance: Grace and Timme (1992); Yuengert (1993); Rai (1996); Cummins and Zi (1998); Katrischen and Scordis (1998); Diacon et al. (2002); Eling and Luhnen (2008); Fenn et al. (2008).

${ }^{4}$ Cummins and $\mathrm{Zi}$ (1998) find that the majority of firms with more than US\$1 billion in assets exhibit DRS. Katrischen and Scordis (1998) find that multinational insurers achieve economies of scale only up to a point, and rather than benefiting from scale, the most internationally diverse insurers suffer dieseconomies. Grace and Timme (1992) and Yuengert (1993), instead, find that large insurers tend to exhibit constant returns to scale (CRS) rather than DRS.

${ }^{5}$ DEA, which is briefly presented in Appendix A, has then been widely used to estimate efficiency in a variety of industries and national markets.

${ }^{6}$ DEA, which is a non-parametric technique, basically differs from SFA, which is instead parametric, along three fundamental dimensions: (i) it is non-stochastic so that any departure from the frontier is categorized as inefficiency; (ii) it is directed to each observation rather than to averages (central tendency estimates) over all observations; and, (iii) it identifies and estimates inefficiencies in each output and each input for the entity associated with each observation. 
First, DEA estimates are consistent and generally converge faster than estimates obtained using SFA. ${ }^{7}$ Second, unlike SFA, DEA gives unbiased estimates of firms' productivity even when there is no unique underlying production technology, which is likely to be the case in our sample. ${ }^{8}$ Finally, comparison between application of DEA and SFA to financial companies evidences that, despite the two methods yielding similar results, ${ }^{9}$ DEA estimates are more highly correlated with conventional performance measures. ${ }^{10}$

We estimate TFP increases on a panel of 602 life insurance companies in five European countries (Germany, France, Italy, Spain and the U.K.) between 1997 and 2004. Following Berg et al., Berger and Humphrey, Athanassopoulos et al. and Diacon, ${ }^{11}$ we first compute efficiency at Local (i.e. country) level and then, using projected values, we estimate a Global efficiency estimate. To distinguish between (different types of) best-practice adoption and best-practice innovation, we develop a generalized Malmquist efficiency decomposition which, despite being relatively simple, is an original contribution of this work.

Our findings indicate that productivity increased significantly over the period of analysis. This increase has been mostly due to innovation in best-practices, while bestpractice adoption has been surprisingly small. In other words, after the enactment of the Third Directive, productivity has been driven only very marginally by the harmonization of business behaviour towards best-practices. The impressive increase in productivity of the whole sector has been, instead, driven by best-in-class insurers which substantially improved industry's business practices.

Different factors may have driven such a spectacular improvement in productivity. On the one hand, productivity might have increased thanks to technological advancement (in particular in information technology). On the other hand the increase in productivity could have been driven by return-enhancement strategies based on higher risk exposure (risk-shifting) by insurers. We have no presumption, in this work, to measure the relative importance of these two, radically different, sources of productivity increase. However, we attempt to test, indirectly, their existence over the period of analysis. We present evidence consistent with the view that technological improvement has substantially affected the production frontier of insurers. However, we find no evidence that productivity has been increased thanks to risk-shifting strategies.

The paper is structured as follows. The next section describes the sample and methodology used in our work (technical details are reported in Appendices A and B). The subsequent section reports and discusses the results about adoption and innovation of best-practices. The penultimate section elaborates on the relevance of risk-shifting in explaining productivity increases. Finally, the last section concludes.

\footnotetext{
${ }^{7}$ Kneip et al. (1988); Grosskopf (1996).

${ }^{8}$ Kittelsen (1995) also shows that possible biases deriving from measurement errors that affect DEA decrease as the number of observations grows. Considering the size of our sample, measurement errors are unlikely to be a significant problem for the analysis.

${ }^{9}$ Casu et al. (2004).

${ }^{10}$ Cummins and Zi (1998).

11 Berg et al. (1993); Berger and Humphrey (1997); Athanassopoulos et al. (2000); Diacon (2001).
} 


\section{Sample and methodology}

In this section we outline the methodological background of our analysis. In the next subsection we provide a brief non-technical description of the methodology we utilize. In the subsequent subsection, we illustrate the sampling process, describe the sample composition and report some selected descriptive statistics.

\section{Methodology}

Measuring productivity requires the estimation of the production frontier, which is the convex hull of all non-dominated feasible combination of inputs and outputs. As mentioned in the previous section, among the different techniques which exist to estimate the production frontier, DEA is the one which is best suited to the analysis we conduct in this study. Like most techniques that estimate production frontiers (including SFA), DEA takes into account that, at least in the short term, inefficiencies may arise. In other words, some companies may be more productive (i.e. more efficient) than others in generating output. Inefficiency of a firm is measured as the distance in inputs and outputs between the firm itself and its projection on the convex hull: the farther away a company is from the frontier, the more it is inefficient and the less it is productive. In other words, productivity and efficiency are inextricably connected concepts (see Appendix A for a formal definition of inefficiency in a DEA framework).

In a dynamic setting the relationship between productivity increases and efficiency is summarised by the Malmquist analysis of DEA scores. The idea underpinning the Malmquist analysis is pretty simple to illustrate (a formalised description is reported in Appendix B). A year-on-year increase in TFP can be decomposed as the combination of two relative "movements". First, the convergence of a company towards the frontier (i.e. an increase in relative efficiency). Second, a movement of the frontier itself with respect to its position in the previous period. The first movement measures the extent to which an inefficient company has come closer to existing best-practices. The second movement is a measure of the extent to which best-practice companies have improved the existing technology. Using the terminology introduced in the previous section, the first movement represents productivity improvement due to adoption of best-practices while the second movement captures productivity increase due to best-practice innovation.

In this work we add to the standard Malmquist decomposition a more fine-grained distinction between different types of best-practice adoption. To do so, we estimate productivity in a two-step process. First, we compute local efficiency scores using DEA on each country subsample: each insurance company is compared, at this stage, only to companies operating in its national environment. This procedure allows us to compare efficiency scores and their evolution at country level and to identify those insurers that are inefficient in comparison to their local competitors. We then project insurance companies to their respective local frontiers: this gives us a set of locally efficient transformations of our original subsamples which, in turn, describe bestpractices observed in each country. A global score is then obtained by applying DEA on these projected units. This gives us the relative efficiency of best-practices in different countries. 
Given the importance of size in determining insurers' efficiency, we adopt a variable returns to scale (VRS) formulation of DEA scores to isolate productivity improvements due to scale adjustment. This decomposes technical inefficiency into two components: scale efficiency (i.e. inefficiency deriving from suboptimal scale) and pure technical efficiency (i.e. the inefficiency of a firm compared to others which are similar in size).

Combining these efficiency measures, the generalized Malmquist decomposition, which we present in Appendix B, allows us to distinguish the relative contribution to TFP change by innovation of best-practices (i.e. technology change of the global frontier) and by different types of adoption of best practices (i.e. movement of individual insurers towards their local frontier, movements of local best-practices towards the global frontier, and increases in scale efficiency).

In accordance with the majority of efficiency studies, we use net premium written (NPW) as a proxy for the output insurance services; input variables are Equity (EQU), Total other Liabilities (OL), Net Technical Reserves (NTR), and total operating and management expenses (ME). ${ }^{12}$

\section{Sample}

We collect annual data from 1997 to 2004 about life insurance companies operating in five European countries: France, Germany, Italy, Spain and the U.K. We resort to Insurance Information and Statistics (ISIS), a large database by Bureau Van Dijk, to collect information on insurance companies' balance sheets and income statements. The ISIS database contains information drawn from the annual report and accounts filed to the respective register of companies in each country. Our sample contains data on life branches and local subsidiaries of international insurance companies. ${ }^{13}$ The five countries included in our study are highly representative of the European life insurance market and, taken together, accounted, in 2004, for 76 per cent of it in terms of premiums. The U.K. was the leading country with a market share of 27.4 per cent, France was second with a 19.8 per cent market share, Italy was third with 12.1 per cent ahead of Germany and Spain with 11.9 per cent and 5 per cent respectively. ${ }^{14}$

Our sample consists of 2,961 observations on 602 life insurance companies. The distribution of the sample across years and countries is reported in Table 1.

As shown in Table 1, 45.70 per cent of the observations are relative to 258 companies operating in Germany, 12.73 per cent in France (80 companies), 12.36 per cent in Italy (70 companies), 10.06 per cent in Spain (58 companies) and 19.15 per cent in the U.K. (136 companies). The number of companies included in the sample is quite balanced across years.

${ }^{12}$ In the insurance industry, labour cost is preferred to headcount because of the widespread practice of outsourcing administrative and sales functions.

${ }^{13}$ For instance, considering Allianz Group, the sample contains all its European subsidiaries (AGF Insurance operating in France, Allianz Cornhill Insurance plc in the U.K., RAS and GeniaLloyd in Italy) and the unconsolidated accounts of the German life branch (Allianz Lebensversicherungs AG).

${ }^{14}$ CEA Statistics (2005). 
Table 1 Sample distribution by country and year

\begin{tabular}{lcccccr}
\hline & Germany & France & Italy & Spain & United Kingdom & Total \\
\hline 1997 & 157 & 50 & 35 & 9 & 71 & 322 \\
1998 & 152 & 62 & 45 & 44 & 70 & 373 \\
1999 & 165 & 51 & 43 & 46 & 78 & 383 \\
2000 & 155 & 48 & 46 & 43 & 80 & 372 \\
2001 & 162 & 44 & 49 & 42 & 67 & 364 \\
2002 & 164 & 45 & 53 & 38 & 60 & 360 \\
2003 & 193 & 41 & 53 & 40 & 70 & 398 \\
2004 & 205 & 36 & 42 & 36 & & 389 \\
& & & & & 567 & 136 \\
\# observations & 1,353 & 377 & 366 & 298 & 58 & 602 \\
\# companies & 258 & 80 & 70 & & & 2,961 \\
\hline
\end{tabular}

Accounting data, converted into Euros using year-end exchange rates and deflated using consumer price index (source OECD, reference year is 2000), are made comparable as a result of the EU Insurance Accounts Directive which came fully into operation in 1996. We report an indication of the relative size of sample companies by country and size quartiles in Table 2.

Significant differences in the size distribution of insurers emerge from Table 2. German companies are concentrated in the first quartile: 37 per cent have average total assets below 150 million euros. A substantial fraction of Spanish companies belongs to the second and third size quartiles and only 2 per cent are in the top quartile. In the U.K., on the contrary, the fraction of companies in the top quartile (i.e. above 4,450 million euros) is 46 per cent. Finally in Italy and France the size distribution is more levelled. ${ }^{15}$

Descriptive statistics of Input and Output variables used in the efficiency analysis, by country, are provided in Table 3 .

Table 3 confirms that average size is substantially different across sample countries. English and French companies are the largest in terms of output: the average English firm has NPW of 1,016.7 million euros, French companies have average premiums of 751.6 million euros compared to an average of 586.6 million euros. Conversely, Spanish and German firms are significantly below the mean with, respectively, 249.7 and 412.1 million euros average NPW. This confirms that English and French insurers are, on average, larger, consistently with figures in Table 2. English and French companies are also the largest in terms of EQU with respectively 506.9 and 245.6 million euros. Spanish and German insurers are the smallest with, respectively, 51.1 and 58.0 million euros of EQU.

\section{Results}

In this section we present and discuss our main findings. We begin in the next subsection by describing technical and scale efficiency scores at both local and global

\footnotetext{
${ }^{15}$ To measure the extent to which these differences are statistically significant, we test whether median size is equal across countries. The null hypothesis is strongly rejected $\left(\chi^{2}(4)=190.15, p\right.$-value $\left.<0.001\right)$.
} 
Table 2 Sample distribution by size and country

\begin{tabular}{|c|c|c|c|c|c|}
\hline & 1st quartile & 2nd quartile & 3rd quartile & 4th quartile & Total \\
\hline Germany & $\begin{array}{c}95 \\
(37 \%)\end{array}$ & $\begin{array}{c}62 \\
(24 \%)\end{array}$ & $\begin{array}{c}54 \\
(21 \%)\end{array}$ & $\begin{array}{c}47 \\
(18 \%)\end{array}$ & $\begin{array}{c}258 \\
(100 \%)\end{array}$ \\
\hline France & $\begin{array}{c}14 \\
(18 \%)\end{array}$ & $\begin{array}{c}24 \\
(30 \%)\end{array}$ & $\begin{array}{c}18 \\
(23 \%)\end{array}$ & $\begin{array}{c}24 \\
(30 \%)\end{array}$ & $\begin{array}{c}80 \\
(100 \%)\end{array}$ \\
\hline Italy & $\begin{array}{c}16 \\
(23 \%)\end{array}$ & $\begin{array}{c}18 \\
(26 \%)\end{array}$ & $\begin{array}{c}20 \\
(29 \%)\end{array}$ & $\begin{array}{c}16 \\
(23 \%)\end{array}$ & $\begin{array}{c}70 \\
(100 \%)\end{array}$ \\
\hline Spain & $\begin{array}{c}15 \\
(26 \%)\end{array}$ & $\begin{array}{c}22 \\
(28 \%)\end{array}$ & $\begin{array}{c}20 \\
(34 \%)\end{array}$ & $\begin{array}{c}1 \\
(2 \%)\end{array}$ & $\begin{array}{c}58 \\
(100 \%)\end{array}$ \\
\hline United Kingdom & $\begin{array}{c}11 \\
(8 \%)\end{array}$ & $\begin{array}{c}24 \\
(18 \%)\end{array}$ & $\begin{array}{c}39 \\
(29 \%)\end{array}$ & $\begin{array}{c}62 \\
(46 \%)\end{array}$ & $\begin{array}{c}136 \\
(100 \%)\end{array}$ \\
\hline Total & $\begin{array}{c}151 \\
(25 \%)\end{array}$ & $\begin{array}{c}150 \\
(25 \%)\end{array}$ & $\begin{array}{c}151 \\
(25 \%)\end{array}$ & $\begin{array}{c}150 \\
(25 \%)\end{array}$ & $\begin{array}{c}602 \\
(100 \%)\end{array}$ \\
\hline
\end{tabular}

Note: Number and percentage of insurers divided by asset quartiles and by country. Percentages, in brackets, refer to the number of companies in each quartile class by country. Assets quartiles are calculated from the average value of Total Assets between 1997 and 2004; the first quartile is below 153 million euros; second quartile is between 153 and 1,150 million euros; third quartile is between 1,150 and 4,450 million euros; the fourth quartile is above 4,450 million euros.

Table 3 Input and output variables

\begin{tabular}{lrrrrr}
\hline & $N P W$ & $E Q U$ & $N T R$ & $O L$ & $M E$ \\
\hline Germany & 412.1 & 58.0 & $2,993.4$ & 429.0 & 66.6 \\
France & 751.6 & 245.6 & $5,664.3$ & 276.8 & 23.3 \\
Italy & 676.6 & 151.7 & $2,671.8$ & 223.4 & 13.2 \\
Spain & 249.7 & 51.7 & $1,007.2$ & 62.9 & 3.9 \\
United Kingdom & $1,016.7$ & 506.9 & $8,969.1$ & 371.0 & 51.1 \\
Total & 586.6 & 178.2 & $4,229.1$ & 336.2 & 45.2 \\
\hline
\end{tabular}

Note: Average values by country (from 1997 to 2004) of the Input and Output variables. EQU is the value of equity, NTR is the total value of Net Technical Reserves, OL is total value of other liabilities, ME are the management expenses. Figures are converted using year-end exchange rates and deflated by consumer price index (source: OECD). Values are in million euros (reference year: 2000).

levels. We then present the results on the relative importance of different types of adoption and innovation in explaining TFP increase in our sample.

\section{Technical and scale efficiency}

Table 4 reports the pure technical and scale efficiency scores at both the local and global analysis by country.

Our results indicate the presence of substantial technical inefficiencies at local level and, more interestingly, they show that significant differences exist among sample 
Table 4 Technical and scale efficiency

\begin{tabular}{lccr}
\hline & Local & Global & Scale \\
\hline Germany & 0.668 & 0.642 & 0.881 \\
France & 0.794 & 0.308 & 0.893 \\
Italy & 0.599 & 0.810 & 0.940 \\
Spain & 0.548 & 0.860 & 0.933 \\
United Kingdom & 0.415 & 0.854 & 0.909 \\
Total & 0.615 & 0.683 & 0.900 \\
\hline
\end{tabular}

Note: Average local and global technical and scale efficiency scores from 1997 to 2004 by country. Efficiency values are computed yearly by DEA with variable return to scale (VRS) assumption. Input variables are Equity, Net Technical Reserves, Other Liabilities and Management Expenses. Output variable is the value of Net Premium Written. Local efficiency scores are obtained by estimating DEA for each country separately. Global efficiency scores are obtained by estimating DEA on a pooled sample of projections onto local frontiers.

countries in this respect. ${ }^{16}$ In particular, French insurers show the highest average values of efficiency with respect to their own frontier, while English insurers appear as the least efficient. ${ }^{17}$ Extreme care should be paid in interpreting these results, since local efficiency levels refer to different frontiers. The difference between French and English average local efficiency, for instance, does not automatically imply that French insurers are on average more efficient than English ones in absolute terms but, rather, that they are on average closer to their national production frontier.

The analysis of global efficiency scores, reported in Table 4, reveals that local frontiers are actually significantly different across countries. ${ }^{18}$ The French local frontier is significantly below (0.308), while the Spanish and U.K. frontiers are significantly above $\left(0.860\right.$ and 0.854 respectively), the European average $(0.683) .{ }^{19}$ The combined analysis of local and global scores gives some interesting insights. French insurers operate near their local efficient frontier which, however, is well below that of other European competitors. On the contrary, in the U.K., there is a higher variability

${ }^{16}$ We use a Kruskal-Wallis test to verify the null hypothesis that all five countries follow the same local efficiency distribution. The null hypothesis is strongly rejected $(p<0.001)$.

${ }^{17}$ A non-parametric Mann-Whitney test is used to test differences between pairs of countries. The null hypothesis that the mean local efficiency of the French insurers equals that of the English companies is strongly rejected $(p<0.01)$.

${ }^{18}$ A Kruskal-Wallis test strongly rejects $(p<0.001)$ the null hypothesis that global efficiency scores follow the same distribution in different countries.

${ }^{19}$ These results are confirmed by an ANOVA test on the probability that an insurer will be on the global frontier (Global efficiency score equal 1) depending on the country in which it operates. Two regularities emerge from this analysis: French projected units are significantly less likely (between 11.0 and 18.8 per cent) to be fully efficient than those from all other countries in our sample $(p<0.01)$. Conversely, English projected units are significantly more likely (between 7.7 and 18.8 per cent) to be on the European frontier than those from all other countries $(p<0.05$ or $p<0.01)$. Results of this supplementary analysis, which is not reported here in full for the sake of concision, are available upon request. 
Table 5 Scale efficiency across size quartiles

\begin{tabular}{lccccc}
\hline & 1st quartile & 2nd quartile & 3rd quartile & 4th quartile & Total \\
\hline Germany & 0.835 & 0.905 & 0.951 & 0.881 & 0.881 \\
France & 0.767 & 0.980 & 0.980 & 0.851 & 0.893 \\
Italy & 0.869 & 0.982 & 0.948 & 0.869 & 0.940 \\
Spain & 0.813 & 0.985 & 0.976 & 0.789 & 0.933 \\
United Kingdom & 0.919 & 0.950 & 0.959 & 0.842 & 0.909 \\
Total & 0.839 & 0.945 & 0.959 & 0.859 & 0.900 \\
\hline
\end{tabular}

Note: Scale efficiencies are computed by DEA with variable returns to scale (VRS) assumption on units projected from their respective local VRS frontier. Size quartiles are calculated from the value of Total Assets of firm-year observations; the first quartile is below 227 million euros; second quartile is between 227 and 1,367 million euros; third quartile is between 1,367 and 5,075 million euros; the fourth quartile is above 5,075 million euros.

in the level of efficiency but the U.K. frontier dominates those of other European countries. $^{20}$

Table 5 reports scale efficiency scores across size quartiles. Scale efficiency is substantially higher in the second and third quartile ( 0.945 and 0.959 respectively) than in the first and fourth quartile ( 0.839 and 0.859 respectively). This suggests that the CRS portion of the frontier is mostly in the mid two size quartiles. It should be noted however that the loss in efficiency is quite limited: other things being equal, companies in the lowest quartile are only 16.1 per cent less productive than they would be if they were operating in CRS. Differences among sample countries mirror different size distributions of local insurers reported in Table 2. Germany (scale efficiency 0.881) is for instance the country with the highest fraction of firms in the first quartile. The U.K. (scale efficiency 0.909) is instead the one with the highest fraction of firms in the last quartile. Accordingly, Germany is scale inefficient because its companies are on average "too small" (i.e. operate in IRS), while U.K. insurers are scale inefficient because often they are too large (i.e. operate in DRS). ${ }^{21}$

\section{Adoption vs. innovation}

Using the methodology described in section 'Methodology' and formalised in Appendix B, we use DEA scores to measure TFP change and its determinants. Results are reported in Table 6.

Between 1997 and 2004 European insurers increased their TFP by an average of 6.71 per cent per year. This TFP change is mostly driven by improvements in global

${ }^{20}$ Our analysis confirms that results obtained by studies conducted only on a local scale may be severely flawed. Moving from a local to a cross-country analysis dramatically changes the interpretation of DEA results. French firms appear extremely efficient when compared on a within-country basis. However, when the analysis is carried out at a EU-wide scale the French efficient frontier proves to be significantly below that of other countries.

${ }^{21}$ See section 'Optimal scale' for further evidence about the optimal scale of operation. 
Table 6 Evolution of technical efficiency by country

\begin{tabular}{lcccccr}
\hline & \multicolumn{9}{c}{ Adoption } & Innovation & $\begin{array}{c}\text { TFP change } \\
(\%)\end{array}$ \\
\cline { 2 - 5 } & $\begin{array}{c}\text { Scale } \\
(\%)\end{array}$ & $\begin{array}{c}\text { Local } \\
(\%)\end{array}$ & $\begin{array}{c}\text { Global } \\
(\%)\end{array}$ & $\begin{array}{c}\text { Overall } \\
(\%)\end{array}$ & & \\
\hline Germany & 1.87 & -0.95 & -2.65 & -1.73 & 5.84 & 4.11 \\
France & 0.62 & 3.55 & 1.91 & 6.08 & 5.91 & 11.99 \\
Italy & 0.21 & 5.75 & -2.56 & 3.41 & 10.67 & 14.08 \\
Spain & 1.06 & -5.53 & -2.62 & -7.10 & 5.20 & -1.90 \\
United Kingdom & -1.09 & 3.84 & -0.48 & 2.27 & 7.36 & 9.62 \\
Total & 0.92 & 0.82 & -1.70 & 0.04 & 6.67 & 6.71 \\
\hline
\end{tabular}

Note: Figures are obtained by generalized Malmquist analysis on the Local and Global frontiers as described in section 'Methodology' and Appendix B.

best-practices (i.e. innovation) which, alone, contributed to 6.67 per cent on a yearly basis. The contribution of best-practice adoption is instead very limited. Overall bestpractice adoption, in its three components, contributed to TFP growth by only 0.04 per cent. This last figure is however the result of conflicting forces. Size adjustment has a significantly positive effect $(+0.92$ per cent) and the same is true for convergence towards local best-practices $(+0.82$ per cent). We find, however a divergence from global best-practices which negatively affects overall TFP growth $(-1.70$ per cent) almost offsetting other components of best-practice adoption.

These results show that, since 1997, global best-practices improved significantly but only a few insurers managed to keep the pace of global technology innovation. Indeed, while local convergence played a positive role, meaning that insurers facing stronger competition did, at least partially, catch up with their local competitors, global convergence is negative and almost twice as large, this meaning that in most cases EUwide best-in-class outpaced local best-practices.

This interpretation is confirmed, by a more fine-grained analysis of TFP change, and its components, in different countries. Total TFP change over the period has been negative only for Spain ( -1.90 per cent), due to a negative overall adoption. While a few excellent Spanish insurers kept up relatively well with global best-practices (the global convergence is only slightly less than average: -2.62 per cent), the majority of them actually diverged from the local best-in-class (the local convergence is -5.53 per cent).

The increase in TFP has been impressive for Italy ( +14.8 per cent) and France $(+11.99$ per cent), although for different reasons. The increase in TFP for Italian companies has been mainly driven by innovation $(+10.67$ per cent $)$ and local convergence $(+5.73$ per cent). Italian insurers are actually the ones which best profited from innovation in global best-practices. Altogether, this means that best-practice innovation did not occur as a parallel shift of the production frontier but, rather, some best-practices improved more than others. Production technologies adopted by Italian insurers have been among those which experienced the highest innovation rate.

In the case of France, instead, the most striking result is its global convergence: French best-practices managed not only to keep the pace of global best-practices, but 
actually got closer to them. This should come as no surprise, following the evidence presented in Table 4: the French local frontier had the largest productivity gap to fill and, hence, the largest room for improvement by means of adoption of global best-practices.

Another interesting figure in Table 6 is scale adjustment of U.K. and German insurers (respectively -1.09 and +1.87 per cent). This result might be the side effect of the wave of Mergers and Acquisitions (M\&As) which characterised Europe throughout the period of analysis. M\&As result in an increase in insurer's size which is beneficial for small insurers (i.e. those operating with IRS), like those which dominate in Germany, but is detrimental for large insurers (i.e. those which operate in DRS), most of which are in the U.K.

\section{Technological improvement and risk shifting}

Results reported in the previous section point out that technological change has been extremely important in driving productivity increase in Europe after the enactment of the Third Directive. This finding is however compatible with two possible explanations. First, it could be the result of technical improvement: insurers in Europe, pushed by increased competition and facilitated by the "IT revolution" (i.e. the development of information and telecommunication technologies for front and back office applications), improved their operations and became more productive. Second, it could be driven by risk-shifting: insurers gradually modified their risk attitude and, facilitated by the "financial revolution" (i.e. the availability of financially engineered products, like Collateralized Debt Obligations, which offered higher returns than securities with similar rating), managed to enhance their revenues and, eventually, improve productivity.

We do not have, in this work, the ambition to give a definitive answer to this issue; however, we present in this section two pieces of evidence supporting the fact that, at least in the period we analyse, technical improvements have been preponderant over risk-shifting.

First, we show, in the subsection below, that innovation has been accompanied by a change in the shape of scale economies. Optimal scale has increased and, at the same time, the range of efficient scales has broadened. This can be explained by the increasing importance of capital-intensive, flexible and scalable technologies (such as IT) during this period. This evidence, then, allows us to reject the hypothesis that productivity has increased merely as a consequence of pure risk-shifting.

Second, in the next subsection, we study the extent to which productivity improvement is determined by a change in the observable portion of insurers' risk exposure. We find no evidence that TFP increase has come to the cost of a decline in solvency ratio. Hence, we find no empirical support that risk-shifting (at least for its observable component) had any impact in improving insurer's productivity.

\section{Optimal scale}

A rough estimate of the optimal scale of operation may be obtained by computing which size maximises the probability for an insurer to operate with CRS. To estimate 
this probability we estimate a multinomial logit model on the scale efficiency category (CRS, DRS and IRS) of each insurer by country. We model the probability to be operating respectively at CRS, DRS or IRS as a function of logarithmic size (in terms of Total Assets) as follows:

$$
\begin{aligned}
& \operatorname{Pr}\left(R S_{i}=j \mid \operatorname{LogSize}_{i}\right)=\frac{e^{\alpha_{j}+\beta_{j} \log _{\text {Size }}}}{\sum_{j}\left(e^{\alpha_{j}+\beta_{j} \log _{\text {Size }}}\right)} . \\
& j=C R S, \text { IRS }, \text { DRS }
\end{aligned}
$$

It is easy to derive the optimal scale from Eq. (1) by maximizing the likelihood that an insurer is operating at CRS (i.e. minimizing the likelihood that it is operating at DRS or IRS). Considering, without loss of generality, CRS to be the base case (i.e. imposing $\alpha_{C R S}=\beta_{C R S}=0$ ), "optimal scale" is given by:

$$
\text { OptLogSize }=\frac{\log \left(-\frac{\beta_{I R S}}{\beta_{D R S}}\right)-\left(\alpha_{D R S}-\alpha_{I R S}\right)}{\beta_{D R S}-\beta_{I R S}} .
$$

Optimal size is then a non-linear combination of parameters in Eq. (1), and may be estimated using the delta-method. Results are reported in Table 7.

Unsurprisingly the coefficient of LogSize in all countries for the DRS model is positive (i.e. the likelihood to exhibit DRS increases with size) while it is negative for IRS (i.e. the likelihood to exhibit IRS decreases with size). All coefficients are significant at conventional confidence levels. The optimal LogSize is estimated to be 7.87 which corresponds to about 2,600 million euros, which is slightly below the midpoint of the third size quartile.

To test the extent to which optimal scale has changed over the period of analysis, we estimate Eqs. (1) and (2) on two subsamples, respectively between 1997 and 2000, and between 2001 and 2004. In the second subperiod OptLogSize is 8.08, against 7.55 in the first subperiod. This difference translates in a 69.89 per cent increase in "optimal scale". A second difference which we observe between the two subperiods is that the standard deviation of the optimal size increases from 0.27 to 0.53 . This suggests that the size range which can be considered "optimal" widened substantially. This latter effect is actually far larger than the former. Despite Total Assets of sample firms in the two subperiods increasing by only 31.65 per cent (i.e. less than half the increase in optimal scale), the fraction of companies operating within one standard deviation from the estimated optimal scale increased from 9.52 to 10.99 per cent. This allows us to conclude that the positive and significant size adoption which we report in Table 6 is in fact the result of a more flexible technology which allows a broader set of companies to operate at efficient scale.

This evidence is compatible with the idea that innovation has been driven, at least partly, by technical change. The "IT revolution" changed the operations of insurance companies by giving them access to a set of relatively capital-intensive and increasingly 
Table 7 Size and returns to scale

\begin{tabular}{|c|c|c|c|}
\hline & 1997-2004 & 1997-2000 & 2001-2004 \\
\hline \multicolumn{4}{|l|}{$D R S$} \\
\hline LogSize $\left(\beta_{D R S}\right)$ & $\begin{array}{l}0.475^{* * * *} \\
(0.05)\end{array}$ & $\begin{array}{l}0.600^{* * * *} \\
(0.07)\end{array}$ & $\begin{array}{l}0.407 * * * \\
(0.06)\end{array}$ \\
\hline const. $\left(\alpha_{D R S}\right)$ & $\begin{array}{l}-2.844 * * * \\
(0.37)\end{array}$ & $\begin{array}{l}-4.200^{* * * *} \\
(0.52)\end{array}$ & $\begin{array}{c}-1.955^{* * * *} \\
(0.47)\end{array}$ \\
\hline \multicolumn{4}{|l|}{$I R S$} \\
\hline LogSize $\left(\beta_{I R S}\right)$ & $\begin{array}{c}-0.309 * * * \\
(0.04)\end{array}$ & $\begin{array}{c}-0.422^{* * *} \\
(0.07)\end{array}$ & $\begin{array}{c}-0.259 * * * \\
(0.54)\end{array}$ \\
\hline const. $\left(\alpha_{I R S}\right)$ & $\begin{array}{l}2.897 * * * \\
(0.28)\end{array}$ & $\begin{array}{l}3.161^{* * *} \\
(0.44)\end{array}$ & $\begin{array}{l}2.971 * * * \\
(0.39)\end{array}$ \\
\hline OptLogSize & $\begin{array}{c}7.87 \\
(0.29)\end{array}$ & $\begin{array}{l}7.55 \\
(0.27)\end{array}$ & $\begin{array}{c}8.08 \\
(0.53)\end{array}$ \\
\hline num.obs. & 2,583 & 1,078 & 1,505 \\
\hline$\chi^{2}$ & 292 & 180 & 197 \\
\hline
\end{tabular}

Note: Scale efficiencies are computed by DEA with VRS assumption. The efficiency frontier is obtained comparing all projected units on a yearly basis. The table presents estimates of a multinomial logit model in which the dependent variable is firm's return to scale category, namely DRS, CRS and IRS. CRS is considered as the base case. The independent variable is the logarithm of insurer's total assets. Standard errors are corrected for heteroschedasticity grouping by company and are reported in brackets. ***significant at the 1 per cent level, **significant at the 5 per cent level, *significant at the 10 per cent level. OptLogSize indicates the logarithm of total assets corresponding to which the probability to operate in CRS is maximum and is computed by Delta method from Eq. (2).

flexible and scalable technologies. Capital intensity (i.e. the substitution of labour with capital) explains the increase in average optimal size. Flexibility and scalability explain the increase in the range of optimal size. Neither of these two pieces of evidence would, however, be explained if innovation of best-practices was only driven by risk-shifting.

\section{Risk exposure}

We test more for risk-shifting by verifying whether the overall improvement in productivity is obtained by incrementing risk exposure. We do not have access to detailed information about the composition of insurers' assets and liabilities; however, we can measure a generic indicator of insurers' financial stability: its solvency ratio (i.e. the ratio between Surplus and Total Assets). ${ }^{22}$ Changes in solvency ratio might, as a general tendency, be correlated to shifts in risk taking. Specifically, we analyse the correlation between TFP increases and increases in firm's solvency ratio. In Table 8 we report, for each country, the average level of solvency ratio, its change over time and Pearson and Rank correlation coefficients between increases in TFP and increases in solvency ratio.

${ }^{22}$ We thank an anonymous referee for this suggestion. 
Table 8 Productivity and solvency ratio

\begin{tabular}{|c|c|c|c|c|}
\hline & $\begin{array}{c}S R \text { (level) } \\
(\%)\end{array}$ & $\begin{array}{c}S R \text { (change) } \\
(\%)\end{array}$ & $\begin{array}{c}\text { TFP and SR: Pearson } \\
\text { correlation }\end{array}$ & $\begin{array}{c}\text { TFP and SR: rank } \\
\text { correlation }\end{array}$ \\
\hline Germany & 8.91 & -1.23 & $\begin{array}{l}-0.1207^{* * * *} \\
(0.000)\end{array}$ & $\begin{array}{l}-0.1387^{* * * *} \\
(0.000)\end{array}$ \\
\hline France & 7.70 & -0.02 & $\begin{array}{c}0.0331 \\
(0.6127)\end{array}$ & $\begin{array}{r}-0.0266 \\
(0.7299)\end{array}$ \\
\hline Italy & 6.61 & -1.38 & $\begin{array}{c}0.1367 * \\
(0.0720)\end{array}$ & $\begin{array}{l}0.1992 * \\
(0.084)\end{array}$ \\
\hline Spain & 9.90 & -0.58 & $\begin{array}{l}-0.1306 * * \\
(0.0788)\end{array}$ & $\begin{array}{r}-0.0030 \\
(0.9683)\end{array}$ \\
\hline \multirow{2}{*}{$\begin{array}{l}\text { United } \\
\text { Kingdom }\end{array}$} & 8.78 & 0.21 & 0.0348 & 0.0486 \\
\hline & & & $(0.6086)$ & $(0.4743)$ \\
\hline Total & 8.59 & -0.81 & $\begin{array}{r}-0.0330 \\
(0.1792)\end{array}$ & $\begin{array}{r}-0.0149 \\
(0.5428)\end{array}$ \\
\hline
\end{tabular}

Note: SR is the solvency ratio, obtained dividing Surplus by Total Assets (equity and outstanding long-term debt). Figures in the last two columns are pairwise correlation coefficients and Spearman's rank correlation coefficients for all pairs of TFP change (reported in Table 6) and solvency ratio change. $p$-values reported in brackets. ${ }^{* * *}$ significant at the 1 per cent level, $* *$ significant at the 5 per cent level, *significant at the 10 per cent level.

On average solvency ratio declined $(-0.81$ per cent) in our sample, suggesting that, overall, there has been a slight increase in risk exposure of European life insurers over the period. However, the correlation between TFP increase and solvency ratio increase is not statistically significant. In other words, insurers with higher-than-average TFP increase do not exhibit higher-than-average decrease in their solvency ratio. Thus, we do not find any evidence that the innovation of best practices, followed to the deregulation process and market integration, was obtained by risk-shifting. ${ }^{23}$ Countrylevel correlations shed some more light about the actual link between TFP and solvency. A significant negative relationship between TFP change and solvency ratio change emerges in Germany and, albeit weakly, in Spain, the two countries where average solvency ratio levels are the highest. At the same time, in Italy, where average solvency ratio was the lowest, we find a positive correlation between TFP change and

${ }^{23}$ Along the same lines, we perform other tests which confirm our results. First, we replicate the correlation analysis on the subsample of companies which lie on both the local and global frontiers in two subsequent years. For these firms the contribution of best-practice adoption is, by construction, null and TFP change is totally driven by improvements in global best-practices. Restricting the analysis to these firms, we find that the correlation between TFP change and change in solvency ratio is again negative (equal to -0.1563 and -0.0330 for Pearson and Rank correlation, respectively), but not significant at conventional confidence levels. As a further evidence, we compare the levels of TFP change of different categories of insurers, classified according to quartiles of solvency ratio change. Differences in TFP change between firms with low, medium and high values of change in solvency ratio are not significantly different. 
solvency ratio change. This suggests that, if any, TFP increase is linked to a convergence towards European average levels of solvency ratios rather than to an unconditioned weakening of financial stability. ${ }^{24}$

\section{Conclusions}

The aim of this work was to explore how the regulatory change process succeeded in boosting the productivity of European life insurance companies. We explored how insurers have reacted to increased competition engendered by deregulation and market integration. We disentangle two different effects: best-practice adoption (i.e. imitation of current, both national and international, best-practices, and achievement of economies of scale), and best-practice innovation (i.e. improvement of current bestpractices to gain competitive advantage against rivals). We considered a sample of 602 insurers operating in five different European countries (France, Germany, Italy, Spain and the U.K.), observed from 1997 to 2004. First we estimated, through DEA, the efficiency at both local (by comparing firms operating in the same country) and global (by comparing local efficient frontiers) levels. Then we used a generalized Malmquist decomposition to measure the different components of TFP change.

We found that, between 1997 and 2004, European insurers increased their TFP by an average 6.71 per cent per year. TFP change has mostly been the result of bestpractice innovation, which, alone, would have driven TFP increase to 6.67 per cent on a yearly basis. Best-practice adoption, instead, contributed to TFP growth by only 0.04 per cent. Specifically, we found a positive effect for size adjustment $(+0.92$ per cent) and convergence towards local best-practices ( 0.82 per cent). We found, however, a divergence from global best-practices which negatively affects overall TFP growth $(-1.70$ per cent). Thus, deregulation and integration have not been enough to close the gap between inefficient insurers and the most efficient ones, mainly because the speed of technology change has been too high for inefficient insurers to catch up.

Accordingly, if the objective of the Third Directive was to achieve a productivity increase thanks to the harmonization of business practices, our results show that this objective has been far from achieved. However, deregulation and liberalization sprouted an impressive acceleration of technological change by a minority of best-inclass insurers which pulled the productivity increase of the whole sector.

We also found evidence that technological change caused a substantial increase in the optimal operating scale $(+69.89$ per cent $)$ but, at the same time, that new

\footnotetext{
${ }^{24}$ At a more anecdotal level, we look for a link between TFP improvements and bailouts in the aftermath of the 2007 financial crisis. If bailouts are more likely for insurers with a higher risk exposure, and if risk exposure drives TFP increase by innovation of best-practices, we should observe a high innovation rate for insurers that later faced a bailout. The only pure player insurer (i.e. not into the banking sector) in our sample which was bailed out is Aegon, which received 3 billion euros from the Dutch government in 2008. Four life insurers in our sample belong to the Aegon group: Aegon U.K. Plc, Aegon Lebensversicherungs Aktiengesellschaft, Aegon Seguros de Vida, Ahorro e Inversion SA and Scottish Equitable Plc (which is fully owned by Aegon since 1998). The annual TFP increase due to innovation in best-practices by these insurers over the period of analysis ( 6.07 per cent) is slightly below the mean of the whole sample, giving no support to the hypothesis that innovation is linked to risk-shifting.
} 
180

technologies are more flexible, meaning that the size range in which companies are likely to operate in CRS actually widened. This suggests that productivity increase, and in particular scale adoption, has been caused by technological improvement. Finally, we found no "smoking gun" of risk-shifting: when directly testing the relationship between firm's solvency and TFP, we did not find any evidence that the latter has been improved at the expense of the former.

\section{Acknowledgement}

The authors thank the participants to the 2008 EEA conference, Giancarlo Giudici, Cinzia Daraio and two anonymous referees for helpful comments.

\section{References}

Athanassopoulos, A.D., Soteriou, A., Zenios, S. and Santomero, A.M. (2000) 'Disentangling within- and between- country efficiency differences of bank branches', in S.A.Z. Patrick and P.T. Harker (eds.) Performance of Financial Institutions: Efficiency, Innovation, Regulation, Cambridge: Cambridge University Press.

Banker, R.D., Charnes, A. and Cooper, W.W. (1984) 'Some models for estimating technical and scale inefficiencies in data envelopment analysis', Management Science 30(9): 1078-1092.

Berg, S.A., Forsund, F.R., Hjalmarsson, L. and Suominen, M. (1993) 'Banking efficiency in the Nordic countries', Journal of Banking and Finance 17(2-3): 371-388.

Berger, A. and Humphrey, D. (1997) 'Efficiency of financial institutions: International survey and directions for future research', European Journal of Operational Research 98: 175-213.

Casu, B., Girardone, C. and Molyneux, P. (2004) 'Productivity change in European banking: A comparison of parametric and non-parametric approaches', Journal of Banking and Finance 28(10): 2521-2540.

CEA Statistics (2005) Insurance in Europe, the European insurance and reinsurance federation, Technical report.

Charnes, A., Cooper, W.W. and Rhodes, E. (1978) 'Measuring the efficiency of decision making units', European Journal of Operational Research 2(6): 429-444.

Cummins, J.D. and Rubio-Misas, M. (2006) 'Deregulation, consolidation and efficiency: Evidence from the Spanish insurance industry', Journal of Money, Credit and Banking 38(2): 323-355.

Cummins, J.D. and Zi, H. (1998) 'Comparison of frontier efficiency methods: An application to the U.S. life insurance industry', Journal of Productivity Analysis 10(2): 131-152.

Cummins, J.D., Turchetti, G. and Weiss, M.A. (1996) Productivity and technical efficiency in Italian insurance industry, Technical report, Wharton School Working Paper series.

Cummins, J.D. and Weiss, M. (2000) 'Analyzing firm performance in the insurance industry using frontier efficiency and productivity methods', in G. Dionne (ed.) Handbook of Insurance, Dordrecht: Kluwer Academic Publishers.

Diacon, S., Starkey, K. and O'Brien, C. (2002) 'Size and efficiency in European long-term insurance companies: An international comparison', The Geneva Papers on Risk and Insurance-Issues and Practice 27(3): 444-466.

Diacon, S.R. (2001) The efficiency of UK general insurance companies, Technical report, Centre for Risk and Insurance Studies, University of Nottingham.

Eling, M. and Luhnen, M. (2008) Frontier efficiency methodologies to measure performance in the insurance industry: Overview and new empirical evidence, Technical report, University of St. Gallen Working Papers on Risk Management and Insurance Paper No. 86.

Ennsfellner, K.C., Lewis, D. and Anderson, R.I. (2004) 'Production efficiency in the Austrian insurance industry: A Bayesian examination', Journal of Risk and Insurance 71(1): 135-159.

Färe, R., Grosskopf, S., Lindgren, B. and Roos, P. (1992) 'Productivity changes in Swedish pharmacies 1980-1989: A non-parametric Malmquist approach', Journal of Productivity Analysis 3(1-2): 85-101.

Fecher, F., Kessler, D., Perelman, S. and Pestieau, P. (1993) 'Productive performance of the French insurance industry', Journal of Productivity Analysis 4(1-2): 77-93. 
Fenn, P., Vencappa, D., Diacon, S., Klumpes, P. and O'Brien, C. (2008) 'Market structure and the efficiency of European insurance companies: A stochastic frontier analysis', Journal of Banking and Finance 32(1): 86-100.

Fuentes, H., Grifell-Tatje, E. and Perelman, S. (2001) 'A parametric distance function approach for Malmquist productivity index estimation', Journal of Productivity Analysis 15(1): 79-94.

Grace, M.F. and Timme, S.G. (1992) 'An examination of cost economies in the United States life insurance industry', Journal of Risk and Insurance 59: 72-103.

Grosskopf, S. (1996) 'Statistical inference and nonparametric efficiency: A selective survey', Journal of Productivity Analysis 7(2-3): 161-176.

Katrischen, F.A. and Scordis, N.A. (1998) 'Economies of scale in services: A study of multinational insurers', Journal of International Business Studies 29(2): 305-324.

Kessner, E. and Polborn, M. (1999) 'Eine effizienzanalyse der deutschen lebensversicherer - die best practice methode', Zeitschrift für die Gesamte Versicherungswissenschaft 88(2-3): 469-488.

Kittelsen, S.A.C. (1995) Monte Carlo simulations of DEA efficiency measures and hypothesis tests, Technical report 09/1999, Department of Economics, University of Oslo.

Kneip, A., Park, B. and Simar, L. (1988) 'A Note on the convergence of nonparametric DEA estimators for production efficiency scores', Econometric Theory 14(6): 783-793.

Mahlberg, B. and Url, T. (2000) The transition to the single market in the German insurance industry, Technical report, Vienna University of Economics and Business Administration.

OECD (2000) Consumer Prices. Paris, France: OECD Publications.

Rai, A. (1996) 'Cost efficiency of international insurance firms', Journal of Financial Services Research 10: 213-233.

Rees, R. and Kessner, E. (1999) 'Regulation and efficiency in European insurance markets', Economic Policy 14(29): 363-398.

Yuengert, A.M. (1993) 'The measurement of efficiency in life insurance: Estimates of a mixed normalgamma error model', Journal of Banking and Finance 17(2-3): 483-496.

\section{About the Authors}

Fabio Bertoni, PhD, CFA, is Assistant Professor at the Department of Management, Economics and Industrial Engineering (DIG) of Politecnico di Milano. His research activity is in the field of corporate finance and, in particular, focuses on the link between firm performance (including growth, innovation, profitability and productivity) and ownership structure, with a particular emphasis on the role of institutional investors such as Venture Capital and Sovereign Wealth Funds.

Annalisa Croce, $\mathrm{PhD}$, is Assistant Professor at the Department of Management, Economics and Industrial Engineering (DIG) of Politecnico di Milano. Her main fields of interest are Entrepreneurial Finance and Productivity and Efficiency Analysis. Her research focuses on venture capital financing and performance of firms backed by different types of venture capitalists and comparative performance analysis and regulation issues in insurance and energy sectors. 


\section{Appendix A}

\section{Data envelopment analysis}

DEA methodology, developed by Charnes et al., ${ }^{25}$ proposes an algorithm to compute technical efficiency, obtaining the weights that maximise productivity (the ratio outputs/inputs) for each unit of analysis. We use input-oriented DEA where outputs are fixed and the objective is to minimise input. The efficiency of a given decisionmaking unit (DMU) $o$, which uses $m$ inputs to produce $s$ outputs, relative to $n-1$ other DMUs is calculated as:

$$
E_{C R S}\left(y_{o}, x_{o}\right)=D\left(y_{o}, x_{o}\right)=\min \theta
$$

subject to:

$$
\begin{aligned}
& y_{r o} \leqslant \sum_{j=1}^{n} \lambda_{j} y_{r j}, \quad r=1,2, \ldots, s, \\
& \theta x_{i o} \geqslant \sum_{j=1}^{n} \lambda_{j} x_{i j}, \quad i=1,2, \ldots, m, \\
& \lambda_{j} \geqslant 0, \quad j=1,2, \ldots, n,
\end{aligned}
$$

where $x_{i o}$ is the $i^{\text {th }}$ input, $y_{i o}$ is the $r^{\text {th }}$ output for the DMU, and $\lambda_{j}$ is an $S \times 1$ intensity vector. The firms for which the elements of $\lambda_{j}$ are nonzero constitute the DMU's reference set. The result of the algorithm is a set of efficiency scores, where the technical efficiency of $o$ is computed by $\theta_{o}$ and determines the amount by which observed input can be proportionally reduced, while still producing the given output level. These efficiency scores are based on the definition of an efficient frontier composed of observed and "virtual" units: the units for which the efficiency score is equal to 1 are considered efficient, while the remaining units have a score $\theta<1$, representing the "distance" of these units from the efficiency frontier, $D\left(y_{o}, x_{o}\right)$. This model, called CCR, after the names of its developers ${ }^{25}$ assumes CRS.

A basic DEA-model variation allows the presence of VRS in computing efficiency scores. This is known as the BCC model. ${ }^{26}$ The BCC model differs from the CCR model for an additional constraint:

$$
E_{V R S}\left(y_{o}, x_{o}\right)=D\left(y_{o}, x_{o}\right)=\min \theta
$$

\footnotetext{
${ }^{25}$ Charnes et al. (1978).

${ }^{26}$ Banker et al. (1984).
} 
subject to:

$$
\begin{aligned}
& y_{r o} \leqslant \sum_{j=1}^{n} \lambda_{j} y_{r j}, \quad r=1,2, \ldots, s, \\
& \theta x_{i o} \geqslant \sum_{j=1}^{n} \lambda_{j} x_{i j}, \quad i=1,2, \ldots, m, \\
& \lambda_{j} \geqslant 0, \quad j=1,2, \ldots, n, \\
& 1=\sum_{j=1}^{n} \lambda_{j},
\end{aligned}
$$

This convexity constraint ensures that the firm is compared against other firms with similar size. The ratio between CCR and BCC results provide information about the "scale efficiency", that is the capability of the systems in reaping all the benefits in terms of scale effects the ability of a unit in using a determined level of input given its dimension:

$$
S E=\frac{E_{C R S}}{E_{V R S}}
$$

\section{Appendix B}

\section{Adoption and innovation measures}

Our methodology is based on a three-step process. The first step is to determine the local efficiency frontiers using DEA under VRS. We build one frontier for each country $j$ and each year $t$. Let $j_{i}$ be the country in which the generic insurer $i$ operates and $\Gamma_{j}=\left\{i \mid j_{i}=j\right\}$ be the set of all insurers which operate in country $j$. Local frontiers are built including in each year $t$ all insurers in $\Gamma_{j}$; we thus have one local frontier for each year $t$ and country $j$. By doing so we can determine the generic distance $D L_{i, t}^{j, \tau}$ which separates insurer $i$ in year $t$ from the $(j, \tau)$ frontier, that is the frontier representing best-practices adopted by insurers $\Gamma_{j}$ in year $\tau$ (Appendix A explains how this distance is computed). We are particularly interested in the distances between insurer $i$ in year $t$ and its current local frontier, that is the frontier $\left(j_{i}, t\right)$ of all insurers $\Gamma_{j_{i}}$ which operate in its own country in year $t: D L_{i, t}^{j_{i}, t} \geqslant 1$. The reciprocal of this distance captures the relative efficiency of insurer $i$ with respect to its local competitors in year $t: E L_{i,}=\left(D L_{i, t}^{j_{i}, t}\right)^{-1} \in(0,1]$. It should be stressed that $D L_{i, t}^{j_{i}, t}$ is directly comparable with $D L_{k, \tau}^{j_{k}, \tau}$ only if $j_{i}=j_{k}$ and $t=\tau$. In other words local distances (and hence local efficiencies) are directly comparable only if they are relative to the same frontier.

The second step of the analysis performs the between-countries analysis. Following Berg et al., Berger and Humphrey, Athanassopoulos et al. and Diacon, ${ }^{11}$ we project each insurance company $i$ on its own "local" frontier $(j, t)$ to obtain a set of country and year-specific best practices whose only possible source of local inefficiency is, if any, scale inefficiency (this because we use DEA under VRS). We then run again DEA 
on all these projected DMUs and estimate a "global" frontier using, again, DEA under VRS assumption. We thus have one global frontier for each year $t$. By doing so we obtain a generic distance $D G_{i, t}^{\tau}$ which measures the distance between the $i^{\text {th }}$ local best-practice in year $t$ (i.e. insurer $i$ in year $t$ projected onto the $\left(j_{i}, t\right)$ frontier) and the global frontier in year $\tau$. As a special case, $D G_{i, t}^{t} \geqslant 1$ measures the distance between local best-practice $i$ and global best-practices in the same year and its reciprocal measures local best-practice $i$ efficiency when compared to EU-wide best practices: $E G_{i, t}=\left(D G_{i, t}^{t}\right)^{-1} \in(0,1]$.

Since both local and global frontiers are estimated under VRS, each insurer also has a scale efficiency given by $S E_{i}^{t}$ which is computed by comparing $\mathrm{VRS}_{t}$ and CRS efficiency obtained from the global frontier in year $t$ (see Appendix A for details about how scale efficiency is computed). Please note that, despite the fact that it is computed on the global efficiency frontier, scale efficiency is relative to insurer $i$ and not local best-practice $i$. The reason is that best-practices are projections on a VRS frontier and are hence locally efficient only when conditioning on scale. Hence best-practices maintain any insurer scale inefficiency which is then inherited by the global frontiers.

The third step of the analysis, finally, uses generalized Malmquist efficiency decomposition to compare frontiers in different time periods. The Malmquist productivity index allows to decompose the productivity growth into two components measuring the change in the technology frontier and technical efficiency.

Färe et $a l .{ }^{27}$ define input-oriented Malmquist productivity index, which measures the productivity change of a particular unit $o$ in time $t+1$ and $t$, as:

$$
M_{o}=\left[\frac{D_{o}^{t}\left(y_{o}^{t+1}, x_{o}^{t+1}\right)}{D_{o}^{t}\left(y_{o}^{t}, x_{o}^{t}\right)} \frac{D_{o}^{t+1}\left(y_{o}^{t+1}, x_{o}^{t+1}\right)}{D_{o}^{t+1}\left(y_{o}^{t}, x_{o}^{t}\right)}\right]^{1 / 2},
$$

$M_{o}>1$ indicates productivity gain, $M_{o}<1$ indicates productivity losses; and $M_{o}=1$ means no change in productivity from time $t$ to $t+1$.

Malmquist productivity index can be further decomposed into two components:

$$
\begin{aligned}
M_{o} & =\left[\frac{D_{o}^{t}\left(y_{o}^{t+1}, x_{o}^{t+1}\right)}{D_{o}^{t}\left(y_{o}^{t}, x_{o}^{t}\right)} \frac{D_{o}^{t+1}\left(y_{o}^{t+1}, x_{o}^{t+1}\right)}{D_{o}^{t+1}\left(y_{o}^{t}, x_{o}^{t}\right)}\right]^{1 / 2} \\
& =\underbrace{\frac{D_{o}^{t+1}\left(y_{o}^{t+1}, x_{o}^{t+1}\right)}{D_{o}^{t}\left(y_{o}^{t}, x_{o}^{t}\right)}}_{T E C_{0}} \underbrace{\left[\frac{D_{o}^{t}\left(y_{o}^{t+1}, x_{o}^{t+1}\right)}{D_{o}^{t+1}\left(y_{o}^{t+1}, x_{o}^{t+1}\right)} \frac{D_{o}^{t}\left(y_{o}^{t}, x_{o}^{t}\right)}{D_{o}^{t+1}\left(y_{o}^{t}, x_{o}^{t}\right)}\right]^{1 / 2} .}_{F S_{0}} .
\end{aligned}
$$

The first component $T E C_{o}$ measures the change in technical efficiency. The second component, $F S_{o}$, measures the technology shift between time period $t$ and $t+1$. A value of $F S_{o}$ greater than 1 indicates a positive shift or technical progress, a value less than 1 suggests a negative shift or technical regress and a value equal to 1 states no shift in technological frontier.

\footnotetext{
${ }^{27}$ Färe et al. (1992).
} 
Suppose, for instance, that $D G_{i, t}^{t}<D G_{i, t}^{t+1}$ : this means that the local best practice $i$ in year $t$ is farther away from global frontier $t+1$ than it is from local frontier $t$. In relative terms, considering $(i, t)$ as pivotal, this means that global best-practices against which local best-practice $(i, t)$ is compared to, "improved" from year $t$ to year $t+1$. Hence, technology improvements in best-practices can be obtained by comparing efficiency levels across frontiers computed in different time periods. Another thing which might change over time is $i$ 's distance to its frontier between year $t$ and year $t+1$. For instance, if $D G_{i, t}^{t}>D G_{i, t+1}^{t+1}$ then local best-practice $i$ got closer to its global frontier from $t$ to $t+1$. The overall increase in productivity of local best-practice $i$ is hence given by the composition of the reduction of the distance to the global frontier (or "technical efficiency change"), and the movement of the global frontier itself (or "technology shift"). In addition we should consider that actual insurers are not as efficient as their respective local best-practices and that best-practices can actually be scale inefficient. Thus we can have improvements in productivity of insurer $i$ between $t$ and $t+1$ because of four different factors: (i) scale adjustment: insurers $i$ becomes less scale inefficient (i.e. $S E_{i}^{t+1}>S E_{i}^{t}$ ); (ii) local convergence: insurer $i$ gets closer to local best-practices (i.e. $D L_{i, t+1}^{j_{i}, t+1}<D L_{i, t}^{j_{i}, t}$ ); (iii) global convergence: local best-practices against which insurer $i$ is compared get closer to global best practices (i.e. $D G_{i, t+1}^{t+1}<$ $D G_{i, t}^{t}$ ); and, finally, (iv) innovation: relevant global best-practices improve from $t$ to $t+1$ (e.g. $D G_{i, t}^{t+1}>D G_{i, t}^{t}$ or, $D G_{i, t+1}^{t+1}>D G_{i, t+1}^{t}$ ).

Analytically the total Malmquist index is given by:

$$
M_{i, t+1}=\underbrace{\frac{S E_{i}^{t+1}}{S E_{i}^{t}}}_{(i)} \underbrace{\frac{D L_{i, t}^{j_{i}, t}}{D L_{i, t+1}^{j_{i}, t+1}}}_{(i i)} \underbrace{\frac{D G_{i, t}^{t}}{D G_{i, t+1}^{t+1}}}_{(i i i)} \underbrace{\left(\frac{D G_{i, t}^{t} D G_{i, t+1}^{t}}{D G_{i, t}^{t+1} D G_{i, t+1}^{t+1}}\right)^{1 / 2}}_{(i v)}
$$

where $M_{i, t+1}>1$ indicates productivity gain, $M_{i, t+1}<1$ indicates productivity loss, and $M_{i, t+1}=1$ means no change in productivity from time $t$ to time $t+1$. Taking the logarithm of Eq. (B1) we obtain the increase in $\log (T F P)$ as a sum of the four, abovementioned, components. 